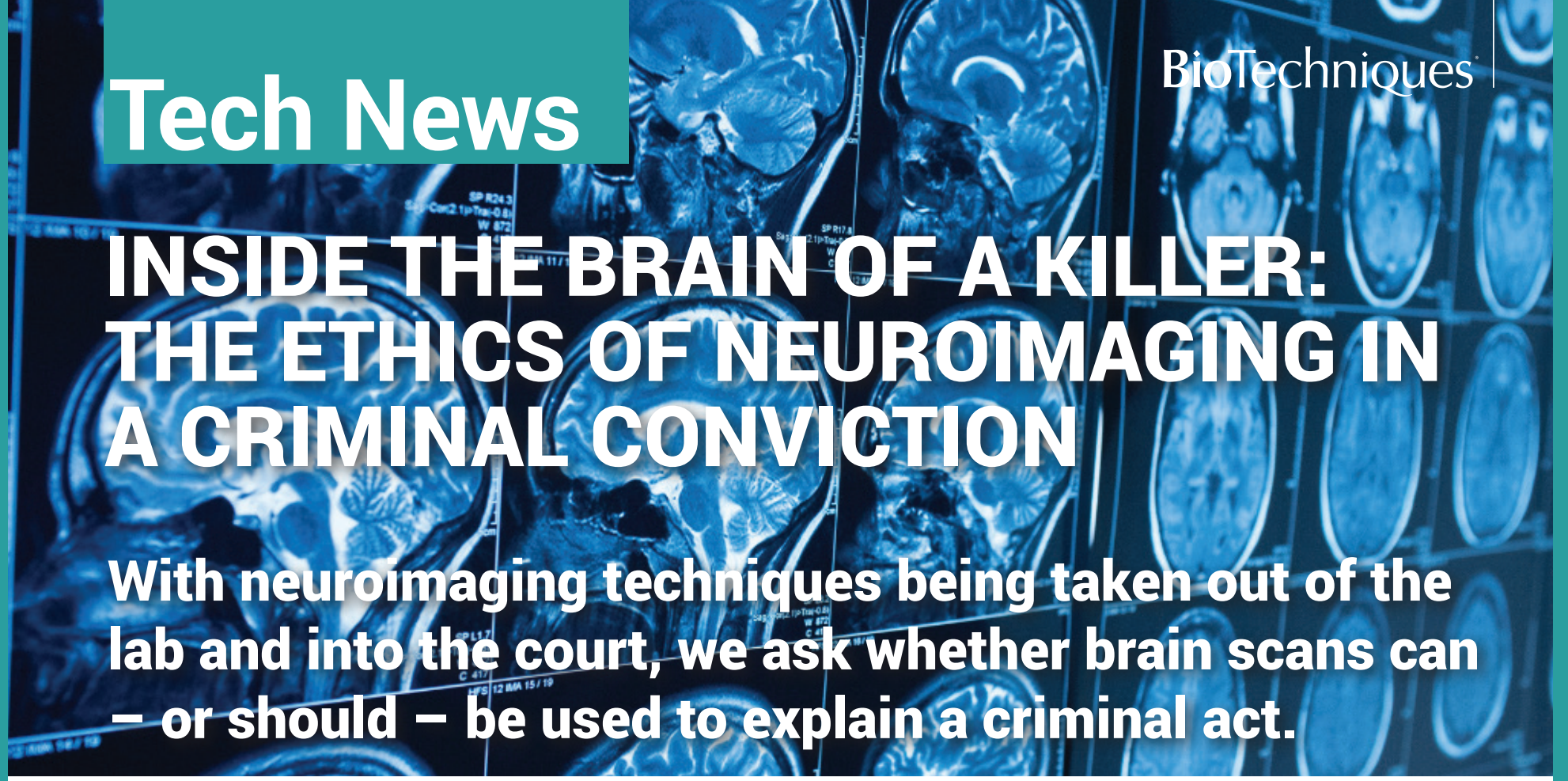

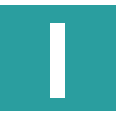

$\mathrm{n}$ the debate of nature versus nurture, what drives someone to commit a crime is hotly contested. Historically, the side consensus falls on is largely influenced by political and sociological views of the time. The now-infamous Franz Josef Gall first proposed the idea that criminal brains differed from the general public with his founding of the pseudoscience of phrenology. His theories of brain localization were viewed as cutting edge during the 19th century and were frequently applied in courts, being used to justify the conviction and subsequent execution of individuals whose skulls matched the so-called profile of a murderer. The attempt to correlate external physical characteristics with behavioral traits led to the reinforcement of many stereotypes of the time, predominantly propagating racial- and class-based discriminatory views [1].

At the end of the Second World War and the fall of the leaders who championed such views, the field of phrenology was widely discredited. Keen to move away from the opinions of earlier fascist dictators, crime was attributed to social or environmental factors - not biology. This attitude persisted for many years, with some still taking this view today. However, with advances in both genetics and neuroscience, the consensus fractured as scientists once again began to question the biological basis of crime

Unlike previous attempts, recent research in this field took a less binary stance, noting that while differences in the brain may make an individual more predisposed to commit crime, these often need to be combined with a multitude of other factors both genetic and environmental - before said criminality occurs. This resulted in the creation of the field of neurocriminology [2]. Neurocriminology combines multiple factors to give a well-rounded view of the those who commit crimes. Research includes genetics, parental influences, early life experiences, hormones, psychophysiology and brain imaging to understand why certain individuals are driven to break the law [2].

Based upon this new field of research, brain imaging was taken out of the lab and into the court room, presenting an ethical quandary for jurors and judges alike; should an individual be held responsible for a crime if their biology is to blame?

\section{ANTISOCIAL ANATOMY}

Structural imaging has been used as a tool in the courtroom for many years, as prosecutors call their expert witnesses, neuroradiologists, to review the scan of the victim and state their cause of death. However, scans of the perpetrators' brains only made their way into court in the 1990s, when defense attorneys hoped to be able to utilize biology to help explain the crime and therefore gain a more lenient sentence from the jury.

Over the years, many legal cases have provided further anecdotal evidence for a biological basis of crime. These largely come in two forms, either stating that the brain differed structurally to begin with, or that a tumor or traumatic brain injury caused damage that resulted in a significant personality change. Alterations in personality due to a structural change in the brain can include increased impulsiveness, depression, aggression, inappropriate sexual behavior, lack of thought control and violence [3]. In a legal setting, brain imaging can confirm that structural changes have occurred in the brain and that has likely resulted in the behavioral change; however, does that waive culpability?

One notable and highly cited case is that of a 40-year-old schoolteacher $[2,4]$. Otherwise healthy, he began to develop an interest in child pornography and displayed a marked increase in sexually deviant behavior. He was soon convicted of child molestation and sentenced to jail. The night before entering prison he complained of severe headaches and was taken to the emergency room where, following an MRI scan, it was revealed that he had a right orbitofrontal tumor. The tumor was removed, his behavior returned to normal and he was deemed safe to go home to his wife and stepdaughter. Several months later the sexually charged behavior returned and it was discovered that the tumor had regrown - it was again removed, and his behavior has remained as it was before ever since [2] 
Russell Swerdlow, the neurologist on the case, noted that behavioral changes as a result of tumors are common, yet this marked the first time it had presented as pedophilia. "What was so striking about this was his inability to act on his knowledge of what was right or wrong," Swerdlow commented [3]. The tumor likely interrupted connections between the orbitofrontal lobe and the amygdala - the region of the brain responsible for emotion and decision making - therefore resulting in diminished impulse control.

The orbitofrontal cortex is one region that has been consistently associated with antisocial or violent behavior, along with the anterior cingulate cortex and the dorsolateral prefrontal cortex - both also located in the frontal lobe. A meta-analysis of 43 imaging studies found that these three prefrontal structures are significantly reduced both in size and function in antisocial individuals [5]. Further, a recent study investigating the difference in grey matter volume of violent versus non-violent criminals found that those who have committed a homicide have reduced grey matter in the regions of the brain associated with emotional processing, behavioral control and social cognition. Including the MRI scans of over 800 prisoners, the study found a significant difference in grey matter volume in the orbitofrontal cortex and anterior temporal lobes in the perpetrators of homicide [6].

In addition, neuroimaging studies have found that patients who suffered injury to these regions of the prefrontal cortex show reduced decision-making capabilities and psychopathic-like behavior. War veterans who had experienced penetrating injuries localized to this area have also been found to be more aggressive than those without injury [2]. Multiple longitudinal studies have demonstrated that brain damage as a result of a traumatic brain injury can increase the risk of criminal behavior, with one study from Sweden finding that, following adjustment for sociodemographic confounders, brain injury could increase criminal behavior up to threefold compared to the general population [7].

\section{WHERE DOES THE BLAME LIE?}

Anatomical differences in the antisocial brain have been found time and time again; however, similar differences have been detected in the brains of non-violent individuals. Noted neurocriminologist Adrian Raine, author of The Anatomy of Violence, found that a PET scan of his own brain more closely mirrored those of the criminals he was researching rather than the control group [1]. Here lies the issue in relying on brain imaging to account for violent behavior - while the brain may be anatomically different, there is no causative proof that gives the structural difference any culpability. Structural differences that lead to reduced empathy or deficient emotional processing may explain why some individuals commit crimes, but it does not excuse it. The regions mentioned have indeed been found in the brains of the most violent sociopaths, yet they are also found in the brains of average people - people who choose not to act on these impulses.

While brain abnormalities may increase the likelihood of criminal behavior, the impact of environment, early life experiences, genetics and epigenetics cannot be understated. Many factors contribute to the development of a criminal. If brain scans are to be entered into the court as evidence, should genetic screens?
What about their education history or examples of traumatic life events? On a case-by-case basis, implying that a structural difference in the brain of the defendant caused him to do it seems a lax argument for persuading the jury to a non-guilty verdict. However, in states and countries where relevant, if the guilty verdict is finalized and the decision is between a life sentence and the death penalty, all of the above could be of interest.

Cases where the criminal behavior is acquired due to a structural change caused by tumor or trauma are more nuanced. Here, the role of neuroimaging is important to the case as it can provide evidence for a reason behind the alteration of their personality. However, does that absolve them of the crime? In the case mentioned above, the schoolteacher retained his moral compass and knew that what he was doing was wrong as evidenced by early attempts to hide his wrongdoings from his family [4]. While the tumor may have caused the impulses - the man gave in to them.

Examples of tumor-influenced behavior have raised questions about responsibility and free will that no one can give a definite answer to. However, these are the questions a jury is expected to answer when presented with brain scans in a criminal case. Daniel Martell, a forensic neuropsychologist, argues that the presentation of scans of any sort in a legal setting simply creates a kind of "Christmas tree effect" in the eyes of the jury. "Lots of people ooh and aah at the pictures. It doesn't tell you anything about a person's behavior," he posited [3]. Many hold the view that brains do not commit crimes - people do; a structural alteration in the brain can neither confirm nor deny the mental state of the arrested individual.

\section{PREDICTING A GUILTY MIND}

According to criminal law, a crime consists of both a physical and a mental element; an actus reus and a mens rea. Mens rea - which translates to 'guilty mind' - refers to the mental state of the individual as they committed the crime and can make all the difference in a conviction. Was the murder premeditated or done on impulse? Did they intend to kill or is it manslaughter? Identifying whether there was criminal intent behind an action or if it was a case of reckless behavior could have significant legal implications.

One study, published in the Proceedings of the National Academy of Sciences, has suggested that the key to identifying criminal intent could also be found in brain scans. While the research is far from courtroom ready, preliminary proof-ofprinciple results from their machine learning-based neuroimaging study suggest it is possible to predict with a high level of accuracy the mental state of someone while they commit a crime [8].

The research group analyzed the functional MRI (fMRI) brain scans of 40 people, taken as they were run through a criminal scenario of smuggling contraband through security at an airport. In the simulated scenario, half knew that they had contraband in their luggage while half knew that they might, but were not certain. In the results they found distinctive brain activity when the individual knew for sure they were carrying contraband - but only when the scenario played out in one specific order. Later, machine learning analysis of the data was able to correctly predict 
whether the individual displayed criminal intent or was just taking a risk between 71 and $80 \%$ of the time [8].

"I see this as a proof of principle that raises more questions than it answers," noted study leader Read Montague (Virginia Tech, USA and University College London, UK) [9]. Likewise, lawyers who were involved in the study were cautious with inferring too much from the results, as it is unknown whether the difference in brain pattern is limited to this one scenario or if it can be applied to situations outside of a lab-based setting. Further research is required; however, the early neural evidence that there is a detectable difference that can determine the mens rea of a crime opens up the possibility of a more biological basis to criminal intent.

That being said, what fMRI can actually tell us is a whole other debate. As demonstrated by a group of researchers at Dartmouth (NH, USA) and a dead salmon [10], the statistical methods used when analyzing data from fMRI studies can result in a large amount of false positives - enough to make a dead salmon appear to be thinking. A study from researchers at Linköping University (Sweden) and the University of Warwick (UK) found that the most widely used software for fMRI analysis can give false-positive rates of up to $70 \%$ [11]. With such a high risk of false-positive, can such a technique be trusted in a courtroom where a false declaration of criminal intent can lead to lifelong imprisonment?

\section{AN ONGOING DEBATE OF FREE WILL}

Whenever the concept of neuroimaging as evidence is discussed, the question of criminal responsibility is raised, as well as the notion of free will. Does it indeed exist, and therefore our decisions and actions are more than just neurological processes in the brain? If not, to what extent does the structure of the brain and changes in these processes influence behavior and choices? While a structural difference or anatomical change may explain a crime, is that enough to absolve a criminal? Is even mentioning it worthwhile?
Evidence has shown that there are structural differences in the brains of individuals that commit crimes, and that brain injury or trauma can lead to significant behavioral changes - in some cases resulting in criminal behavior. Therefore, to discount the neurological effect would be remis - the role of a juror is to review all the evidence prior to making their decision, and neuroimaging is evidence. However, it is worth not overestimating the importance of a scan. As said previously, neurocriminology has introduced a multifaceted view of crime and therefore neuroimaging evidence alone should not be used to pardon, nor prosecute, an individual.

Written by Jenny Straiton \& Francesca Lake

\section{REFERENCES}

1. The Guardian UK. How to spot a murderer's brain (2013). www.theguardian.com/ science/2013/may/12/how-to-spot-a-murderers-brain

2. Glenn AL, Raine A. Neurocriminology: implications for the punishment, prediction and prevention of criminal behaviour. Nat. Rev. Neurosci. 15(1), 54-63 (2014).

3. Davis K. Brain trials: neuroscience is taking a stand in the courtroom. ABA Journal, American Bar Association, DC, USA (2012). www.abajournal.com/magazine/article/ brain_trials_neuroscience_is_taking_a_stand_in_the_courtroom/

4. Burns JM, Swerdlow RH. Right orbitofrontal tumor with pedophilia symptom and constructional apraxia sign. JAMA Neurol. 60(3), 437-440 (2003).

5. Yang $Y$, Raine A. Prefrontal structural and functional brain imaging findings in antisocial, violent, and psychopathic individuals: a meta-analysis. Psychiatry Res. Neuroimaging 174(2), 81-88 (2009).

6. Sajous-Turner $\mathrm{A}$, Anderson $\mathrm{NE}$, Widdows $\mathrm{M}$ et al. Aberrant brain gray matter in murderers. Brain Imaging Behav. 14(5), 2050-2061 (2020).

7. Fazel $S$, Lichtenstein $P$, Grann $M$, Långström $N$. Risk of violent crime in individuals with epilepsy and traumatic brain injury. a 35 -year Swedish population study. PLoS Med. 8(12), e1001150 (2011).

8. Vilares I, Wesley MJ, Ahn W-Y et al. Predicting the knowledge - recklessness distinction in the human brain. Proc. Natl Acad. Sci. USA 114(12), 3222-3227 (2017).

9. Cornwall W. Did you knowingly commit a crime? Brain scans could tell. Science Magazine, DC, USA (2017). www.sciencemag.org/news/2017/03/did-you-knowinglycommit-crime-brain-scans-could-tell

10. Bennett CM, Miller MB, Wolford GL. Neural correlates of interspecies perspective taking in the post-mortem Atlantic Salmon: an argument for multiple comparisons correction. Neurolmage 47(Suppl. 1), S125 (2009).

11. Eklund A, Nichols TE, Knutsson $H$. Cluster failure: Why $f M R I$ inferences for spatial extent have inflated false-positive rates. Proc. Natl Acad. Sci. USA 113(28), 7900-7905 (2016). 